\title{
XIV.
}

\section{Beitrag zur normalen und pathologischen Anatomie des Schläfenbeins mit besonderer Rücksicht auf das kindliche Schläfenbein. \\ Von}

Dr. W. Kiesselbach in Erlangen.

(Hierza Tafel VI u, VII.)

EINLEITUNG.

Die Veranlassung zu vorliegender Arbeit gab zunächst der Wunseh, die Lage des Antrum mastoideum in den verschiedenen Lebensaltern im Verhältnisse zu der äusseren Wandung des Schlüfenbeins zu untersuchen. Im Zusammenhange damit erschien es von Interesse, das Vorkommen, resp. die Häufigkeit bleibender Oeffnungen als Residuen der Fissura mastoideo-squamosa in den verschiedenen Lebensaltern zu constatiren, da die Fissur im ersten Kindesalter direct in das Antrum mastoideum führt, und auch später die Reste derselben wenigstens in indirecter Beziehung zu demselben bleiben.

Durch die Zusammenstellung einer Reihe von Fällen aus den verschiedensten Lebensaltern mit Lücken in der äusseren Warzenhöhlenwand glaube ich einen nicht unwichtigen Beitrag: zur Entscheidung der Frage geliefert zu haben, ob diese Liicken angeboren sind oder nicht, und muss ich mich nach den gefundenen Thatsachen für das erstere entscheiden. Damit dürfte denn auch wohl die Entstehung der spontanen Pneumatocele cranii supramastoidea, sowie der durch die Schëdelwandung direct entstehenden Emphyseme ihre Evklärung finden.

Dagegen fuhrte mich die Vergleichung einer Anzahl von rhachitischen Schläfebeinen von Kindern mit Schädeln Erwachsener zu der Ueberzeugung, dass, abgesehen von der Altersatrophie, die Liicken in der Corticalis der pneumatischen Zellen im Innern des Schädels wohl in den meisten Fällen, wenn nicht ausschliesslich, rhachitischen Ursprunges sind. 
Das gleichzeitige Vorkommen von Einsenkungen der Lamina externa des hinteren Schuppentheiles mit Tiefstand der mittleren Schädelgrube ist ein Umstand, der beim Vorhandensein soleher Einsenkungen bei etwaiger Ausfilhrung der Perforation des Warzenfortsatzes zur äussersten Vorsicht auffordern muss.

Die Mittheilungen über die normale Anatomie des Schläfenbeines finden ihre Begrïndung darin, dass es mir wohl zuerst vergönnt war, eine so grosse und wohlgeordnete Sammlung von Schädeln Heranwachsender zu untersuchen, wie sie die Wiener anatomische Sammlung darbietet.

Für die ausserordentliche Freundlichkeit, mit welcher Herr Hofrath Langer mir die Untersuchung dieser Sammlung gestattete, sage ich demselben meinen aufrichtigen Dank; ebenso Herrn Prosector Dr. Zuckerkandl firr die aufopfernde Mühe, mit welcher er mich bei Benutzung der Sammlung unterstïtzte.

\section{LITẺRATUR.}

Bezold, Die Perforation des Warzenfortsatzes vom anatomisehen Standpunkt aus. M. f. O. 1873. Nr. 11. 1874 . Nr. 1 u. 2. -, Aerztliches Intelligenzblatt. 1874. -, Erkrankungen des Warzentheils. A. f. O. XIII. 1877. - Bürk n er, Kleine Beiträge zur normalen und pathologischen Anatomie des Gehörorgans. A. f. O. XIII. 1878. - Gruber, Lehrbuch der Ohrenheilkunde. Wien 1870. - Untersuchungen über die Anatomie des äusseren Gehörganges. M. f. 0.1868 . Nr. 5 a. 6. - Beiträge zur Anatomie des Schläfebeins etc. Wiener med. Wochenschr. 1867. - Hartmann, Ueber die Perforation des Warzenfortsatzes. Langenbeck's Archiv. XXI. Heft 2. - Heineke, Chirurgische Krankheiten des Kopfes. Pitha und Billroth. III. 1. Abth. - Henle, Handbuch der systematischen Anatomie des Menschen. Knochenlehre. 1871. H y r t 1, Sitzungsberichte der kaiserlichen Academie der Wissenschaften. XXX. Nr. 16. - , Handbuch der topographischen Anatomie. I. 1860. - , Lehrbuch der Anatomie des Menschen. - Joseph, L., Osteologischer Beitrag etc. Zeitschrift für rationelle Medicin. 3. Reihe. XXVIII. 1866. - Kirchner, Ueber das Vorkommen der Fissura mastoideo-squamosa und deren praktische Bedeutang. A. f. O. XIV. 1879. - Kölliker, Entwicklungsgeschichte des Menschen und der höheren Thiere. Leipzig 1879. - Luschka, Die Anatomie des menschlichen Körpers. Tübingen 1867. III. 2. - Virchow's Archiv. XVIII. 1860 . - Rambaud et Renault, Origine et développement des os. Paris 1864. - Schmidt, Ueber emphysematöse Geschwülste am Schädel. I.-D. Würzburg 1871. - Schwantze u. Eysell, Ueber die künstliche Eröffnung d. Warzenfortsatzes. A.f. 0. VII. 1873. April - Schwartze, Pathologische Anatomie des Ohres. Handb. d. pathol. Anat. v. Klebs. Berlin 1878. - Toy nbee, Die Krankheiten des Gehörorgans. Uebersetzt von Moos. Würzburg 1863. - A descriptive catalogue of praeparations illustrative of the diseases of the ear in the museum of Joseph Toynbee. London 1857. - v. Tröltsch, Lehrbuch der Ohrenheilkunde. Leipzig 1877. - Vrolik, A. J., Die Verknöcherung des Schläfenbeines der Säugethiere. Niederländisches Archiv für Zoologie. I. 3. Heft. 1873. - W ernher, Pneumatocele cranii. Deutsche Zeitschrift für Chirurgie. III. 1873. - Wildermuth, Die lufthaltigen Nebenräume des Mittelohres beim Menschen. Leipzig 1877. (Tübinger Dissertation.) $-Z$ u ckerka ndl, Zur Entwicklung des äusseren Gehörganges. M. f. 0. 1873. Nr. 3. - Beitrag zur Anatomie des Schläfebeines. M. f. 0. 1873. Nr. 9. - , 
Zweiter Beitrag zur Anatomie des Schlafebeines. M. f. 0.1874. Nr. 7. - Ueber eine typische Spaltbildung an der hinteren Wand des äusseren Gehörganges. M. f. 0.1878 . S. 46 .

\section{Zur Anatomie des Schuppen-Paukentheils.}

Als äussere Grenze zwischen Schuppen- und Warzentheil des Schläfenbeins der Erwachsenen wurde früher allgemein die Linea temporalis angenommen, obgleich die Existenz jener Spalte, welche beim Neugebornen die äussere Grenze zwischen Schuppe und Warzentheil bezeichnet, schon den älteren Anatomen bekannt war. Somit wurde der ganze hintere Sehuppentheil, weleher bei dem Neugebornen die äussere Wand des Antrum mastoideum bildet, bei dem Erwachsenen mit zu dem Warzentheile gerechnet. Henle-1) gibt zwar an, dass sich die Naht, welche bei dem Neugeborenen Schuppen- und Warzentheil trennt, zuweilen beim Erwachsenen erhalte, doch sucht er ihre Spuren weiter nach vorn, als dieselben in der That auch noch bei dem Erwachsenen zu finden sind "): "Auf der Anssenfläche scheiden sich Schuppen- und Warzentheil beim Erwachsenen nur undeutlich durch eine seichte Rinne, welche von der Incisura parietalis gegen den hinteren Rand des Porus acusticus externus herabzieht..... Der bogenförmige Theil des Randes des Schuppentheils zieht aus der Tiefe des äusseren Gehörganges nach hinten längs der Grenze zwischen Schuppen- und Warzentheil zur Incisura parietalis."

In Wirklichkeit aber betheiligt sich der Warzentheil wohl niemals direct an der Bildung des äusseren Gehörgangs ${ }^{3}$ ), und die äussere Grenze zwischen Schuppe und Warzentheil des Erwachsenen wird durch eine Linie bezeichnet, welche von der Incisura parietalis herab auf dem Processus mastoideus bis etwa zur Höhe des unteren Endes des Porus acusticus externus oder etwas tiefer nach abwärts verläuft, sich dann nach vorn wendet, um in der Incisura mastoidea zu enden. Durch diese Linie wird die äussere Wand des Processus mastoldeus in einen vorderen, meist glatten Schuppenantheil, und einen hinteren rauhen Warzen antheil geschieden. Diese Trennungslinie ist an der von Henle ${ }^{4}$ )

1) Hen le, Handbuch der systematischen Anatomie des Menschen. Knochenlehre. 1871. S. 149.

2) Ebenda S. 139 u. 144.

3) Gruber, Lehrbuch der Ohrenbeilknnde. Wien 1870. S. 23 und : Untersuchungen äber die Anatomie des äusseren Gehörganges etc. M. f. O. 1868. $\mathrm{Nr}, 5$ und 6.

4) 1. c. S. 144 . Fig. 131. 
gegebenen Zeichnung der äusseren Wand des Schläfenbeines deutlich $\mathrm{zu}$ erkennen.

Dagegen bemerkt schon Toy $\mathrm{nbee}$ ), dass ein senkrechter Schnitt, welcher durch das Antrum mastoideum eines etwa zwei Jahre alten Kindes geht, bemerken lässt, dass das Antrum aussen von einem Theil des Schuppenknochens begrenzt wird, welcher nach oben und ein wenig nach hinten vom äusseren Gehörgang liegt.

Dass auch bei dem Erwachsenen diese Platte zum Schuppentheil gehört, hat zuerst $J_{0} \mathrm{e} \mathrm{ph}^{2}$ ) richtig angegeben: "Es ist daher nicht die Linea temporalis die Grenze zwischen Schläfenund Felsenbein, sondern die unvollkommene Sutura petro-squamosa, welche sich meistens senkrecht abwärts von der Incisura parietalis erstreckt und einen grössern oder kleinern Theil des Processus mastoideus dem Schläfenbein zutheilt. Daher gehört die hinter der Linea temporalis gelegene Platte, welche bei Kindern senkrecht abwärts verläuft, bei Erwachsenen unter rechtem Winkel zur Schuppe gebogen ist und die Decke des äusseren Gehörganges bildet, unzweifelhaft zum Schläfenbein."

Nach Joseph beschrieb zunächst J. Gruber's) die Beziehungen des äusseren Theiles der Felsenschuppennaht (welche er zum Unterschiede von dem innern Theile, der Fissura petrosquamosa, als Fissura mastoideo-squamosa bezeichnete), sowie des hintern Schläfebeinabschnittes za Antrum mastoideum und Warzenfortsatz. Auch hat Gruber zuerst auf die praktische Bedeutung der Fissura mastoideo-squamosa aufmerksam gemacht.

Weiter haben dann Schwartze und Eysell ${ }^{4}$ ) gezeigt, dass in späterer Zeit die Fissura mastoideo-squamosa, sowie die Fissura petro-squamosa (zusammen als Felsenschuppennaht bezeichnet) eine Trennung des beim Neugebornen einzelligen Antrum mastoideum in einen Felsentheil und einen Schuppentheil äusserlich anzeigen, indem eine zwischen beiden vollständig durchlaufende Knochenleiste die Trennung in den grösseren, nach hinten, innen

1) J. Toynbee, Die Krankheiten des Gebörorgans. Uebersetzt von Moos. Würzburg 1863. S. 303.

2) L. Joseph, Osteologischer Beitrag etc. Zeitschrift für rationelle Medicin. 3, Reihe. XXVIII. S. 105. 1866.

3) J. Gruber, Beiträge zur Anatomie des Schläfebeines etc. Wiener med. Wochenschrift. 1867.

4) Schwartze und Eysell, Ueber die künstliche Eröffnung des Warzenfortsatzes. A.f. O. VII. S. 165 ff. 1873 . 
und unten gelegenen Felsentheilabschnitt, und den kleineren nach vorn, anssen und oben gelegenen Schuppenabschnitt bewirkt.

Auch Wildermuth ${ }^{1}$ ) hat diese spätere Trennung des urspringlichen Antrum mastoideum in ein Antrum squamosum und ein Antrum petrosum bestätigt.

Endlich gab Kirchner ${ }^{2}$ ) eine Zusammenstellung mehrerer Fälle von Fortleitung entzỉndlicher und katarrhalischer Processe der Paukenhöhle auf die Aussenwand des Warzenfortsatzes. Auch er schreibt, wie Graber, die relative Häufigkeit und Leichtigkeit des Ueberganges solcher Processe auf die äussere Wand des Warzenfortsatzes dem Persistiren von Ueberresten der Fissura mastoide0-squamosa zu, und gibt zur Begründung dieser Ansicht eine statistische Uebersicht der an 300 Schädeln Erwachsener gefundenen Resultate.

Kirchner fand bei diesen 300 Schädeln:

1. beiderseitig vollkommene Spalte . . . . . 5 Proc.

2. links vollkommene, rechts theilweise Spalte $.2,6$ n

3. links vollkommene Spalte, rechts geschlossen 1,6 "

4. rechts vollkommene, links theilweise Spalte - 1,3 "

5 . beiderseitig theilweise Spalte . . . . . 6,6 "

6. links theilweise Spalte, rechts geschlossen . . 4 "

7. rechts theilweise Spalte, links geschlossen . . 2 "

Es erschien mir daher von Interesse, die Verhältnisse der Fissura mastoideo-squamosa auch bei Heranwachsenden zu untersuchen, und gebe ich in Nachstehendem die Resultate der" an 174. Schädeln der Wiener anatomischen Sammlung angestellten Untersuchung.

Die Fissura mastoideo-squamosa der Neugebornen verläuft von der Incisura parietalis in mehrfacher Biegung herab bis nahe zum hintern oberen Ende des Paukenringes, nach vorn begrenzt von dem hintern Rande der äussern Lamelle des sogenannten horizontalen Schuppentheils, während die hintere Begrenzung ron der Pars mastoidea gebildet wird.

In der Regel kann man an dieser Fissur drei Theile unterscheiden: 1. den oberen, nach hinten convexen Theil,

2. den mittlern, nach hinten convexen Theil,

3. den untern, nach hinten concaven Theil.

1) Wildermuth, Die lufthaltigen Nebenräume des Mittelohres beim Menschen. Leipzig 1877. (Tübinger Dissertation.)

2) Kir chner, Ueber das Vorkommen der Fissura mastoideo-squamosa und deren praktische Bedeutung. A. f. O. XIV. 1879. 
Fig. 1 (Taf. VI u. VII). Der obere Theil gehört der Fissura mastoideo-squamosa und der Fissura petro-squamosa gemeinschaftlich an, da die beiden Blätter des hintern Schuppentheils erst unterhalb desselben anseinanderweichen. $\mathrm{Er}$ wird gebildet durch einfache Aneinanderlagerung der Ränder, oder durch Ueberlagerung des Warzentheils durch den Sehuppentheil. Dieser Theil der Fissur erstreckt sich von der Incisura parietalis bis zu einem constant vorkommenden, nach vorn gerichteten Einschnitt der Schuppe herab, welcher bis $2 \mathrm{Mm}$. lang sein kann. Dieser Einschnitt führt in das Antram squamosum (den der Schuppe angehörenden Theil des Antrum mastoideum), und ist in selteneren Fällen der Anfang eines, von der Schuppe allein gebildeten Kanals, der nach unten und vorn zum Antrum squamosum verläuft. In vielen Fällen fehlt dieser obere Theil der Fissur (Fig. 2 Taf. VI u. VII), indem der Schuppenrand von dem eben bezeichneten Einschnitte an mehr nach vorn verläuft. Das hierdurch ausfallende Stück der Schuppe wird dann durch einen Schaltknochen ersetzt, welcher auch mit dem Seitenwandbein verschmelzen kann. In letzteren Fällen liegt die Incisura parietalis direct über dem obern Ende des Antrum mastoideum.

In einem Falle (Schädel eines Erwachsenen) reicht der Schaltknochen, der der ganzen Configuration nach dem obern hintern Theile der Schuppe entspricht, so weit herab, dass er sogar noch über die dem Boden des Antrum mastoideum entsprechende Höhe nach abwärts reicht. Der Schaltknochen bildet nahezu die Hälfte der Schuppenbekleidung des rechten Processus mastoideus. Die Incisura parietalis liegt in Folge dessen tiefer als die Spina supra meatum, und würde eine durch das untere Ende der Incisur mit dem obern Jochbogenrande gezogene Parallele etwa die Mitte der hintern Gehörgangswand treffen. Die Incisur liegt fast $14 \mathrm{Mm}$. unterbalb der vordern obern Wand des Felsentheils, $19 \mathrm{Mm}$. über der Spitze des Warzenfortsatzes, während links die Spitze des Processus mastoideus $37 \mathrm{Mm}$. von der Incisura parietalis entfernt ist.

Der mittlere Theil der Fissura mastoideo-squamosa ist scharf gegen den obern Theil abgesetzt. Von dem beschriebenen Einschnitte an trennen sich die beiden Lamellen des hintern Schuppentheils, ron denen die innere mit dem Tegmen tympani die Fissura petro-squamosa bildet, während die äussere Lamelle das Antrum mastoideum von aussen deckt. Das obere Ende des Antrum mastoideum wird genan dureh die Grenze zwischen 
oberem und mittlerem Drittel der Fissura mastoideo-squamosa bezeichnet. Das untere Ende dieses mittleren Drittels ist durch die Stelle angezeigt, wo die den verticalen von dem horizontalen Theil der Schuppe trennende Linie (s. unten) den hintern Schuppenrand erreicht.

Der untere, nach hinten coneave Theil der Fissur wird begrenzt nach hinten und oben durch die Ursprungsstelle des zukünftigen Processus mastoideus, nach vorn und unten durch den hintern Rand des Schuppenfortsatzes, welcher das hintere Ende des Paukenringes trägt. Dieser Fortsatz ragt nach hinten und unten verschieden weit auf die Oberfläche des Warzenfortsatzes hinüber, so dass er mitunter bis zum Foramen stylo-

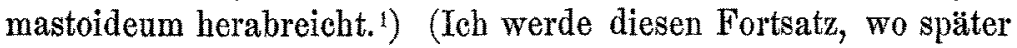
von ihm die Rede sein wird, als Processus tympanicus squamae bezeichnen.) Dieser Fortsatz ist der erste Theil der Schuppe, welcher sich mit dem Warzentheile knöchern vereinigt, und scheint es ausserordentlich selten zu sein, dass zur Zeit der Geburt diese knöcherne Vereinigung noch nicht erfolgt ist. Unter den untersuchten Schädeln der Wiener Sammlung war die Vereinigung der Spitze des Processus tympanicus squamae mit dem Warzentheil nur an fünf Schläfebeinen noch nicht eingetreten, und zwar:

1. an beiden Schläfebeinen eines ain vierten Lebenstage ver storbenen Kindes.

2. am rechten Schläfebein eines am 13. Lebenstage verstorbenen Kindes.

3. beiderseits bei einem Kinde von drei Monaten.

An etwa fünfzig Schläfebeinen Neugeborner, welche ich ausserdem noch hierauf untersucht habe, war die knöcherne Vereinigung bereits vollendet.

Mit zunehmendem Alter schliesst sich die Fissura mastoideosquamosa immer mehr und sind die Verhältnisse hierbei folgende: Zuerst, wie bemerkt, bildet sich die vollständige knöcherne Vereinigung des Processus tympanicus squamae mit der unterhalb der Anlage des Warzenfortsatzes gelegenen Partie des Warzentheils aus. Es schliessen sich zunächst die Mitte und das obere Drittel, während der untere Theil am längsten offen bleibt.

Eine Zusammenstellung dieser Verhältnisse, nach den Lebensjahren geordnet und auf 100 berechnet, gibt nachstehende Tabelle:

1) Gruber l. c. 
Beitrag zur normalen und pathologischen Anatomie des Schläfenbeins. 245

\begin{tabular}{|c|c|c|c|c|c|c|c|c|c|}
\hline $\begin{array}{l}\text { Die Fissura mastoideo- } \\
\text { squamosa ist: }\end{array}$ & 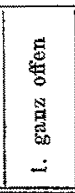 & 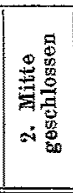 & 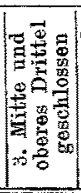 & 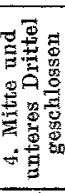 & 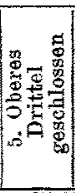 & 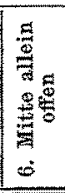 & 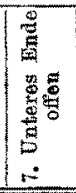 & 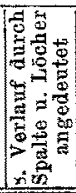 & 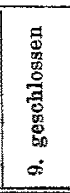 \\
\hline chläfebeine) & 17,30 & 19,23 & & $5 ; 77$ & & - & 8,85 & - & \\
\hline 2. $"(26$ & - & - & 19,20 & 3,80 & & - & 23,10 & - & 53 \\
\hline 3. ", & 4,35 & - & - & - & 4,35 & 2,18 & 39,13 & 17,39 & \\
\hline 4. $"(52$ & & - & 11,54 & & 3,85 & 7,70 & 25,00 & 17,30 & \\
\hline 5. $" \quad(38$ & 7,98 & - & - & - & 5,26 & 2,63 & 23,68 & 13,16 & $4 \pi$, \\
\hline 6.,$\quad 32$ & - & $|3,125|$ & & - & - & 6,25 & 6,25 & 25 & \\
\hline 7. " & - & - & 6 & - & 13,3 & 3,3 & 10,0 & & \\
\hline $8-10 . "$ & - & - & 8,33 & - & $1-$ & - & 4,17 & 16,66 & \\
\hline . & 10,0 & - & 10 & - & - & 10,0 & 3,3 & 6,7 & \\
\hline $19 ., 110$ & - & - & 11,11 & - & - & $=$ & - & $22,22 \mid$ & 66,67 \\
\hline
\end{tabular}

Kirchner (1. c.) fand bei Erwachsenen die Fissur in 77 Proe. der Fälle beiderseits vollkommen geschlossen, während sie in 5 Proc., also an 15 von 300 Schädeln, beiderseits vollkommen offen war. Er fand demnach fur das Offenbleiben der Fissur bei Erwachsenen viel grössere Zahlen, als ich dieselben bei Heranwachsenden constatiren konnte. Unter den 174 Sehädeln, welche ich darauf untersucht habe, war die Spalte beiderseits vollkommen offen nur sechsmal, also in etwa 3,4 Proc. sämmtlicher Fälle. Von diesen Fällen kommen obendrein fünf Fälle auf das Alter unter 10 Jahren, während nach dem 10. Jahre beiderseitiges Offenbleiben der Fissur nur einmal gefunden wurde.

Im Uebrigen sind die von der Fissura mastoideo-squamosa herrithrenden Spalte und Löcher meist von geringer Weite, so dass es mir bei älteren Kindern nur selten gelang, eine Borste durchzuführen, anch in solchen Fällen, wo die Lücke äusserlich einen breiteren Eingang hatte. Nur in seltenen Fällen, besonders bei abnormer Dünnheit der äusseren Wandung führen dieselben breitklaffend zu den Innenräumen des Warzenfortsatzes. (Fig. 3, Taf. VI u. VII.)

Ein eigenthümliches Verbalten in Bezug auf das Offenbleiben des untersten Endes der Fissura mastoideo-squamosa fand ich bei einem 21/2 jährigen Schädel. Der Theil der Fissur, welcher die Anlage des Processus mastoideus umgibt, ist durch das Wachsthum des Zitzenfortsatzes nicht, wie es sonst zu geschehen pflegt, ausgefullt worden. Es sieht aus, als habe ein Wachsthum des Warzenfortsatzes nur nach hinten stattgefunden; mit ihm ist auch der obere Theil des hinteren Schuppenrandes, wie gewöhnlich, nach hinten verlegt, während der Processus tympanicus squamae 
unverändert stehen blieb. Es entsteht hierdurch zwischen Processus tympanicus squamae und der Spitze des Warzenfortsatzes eine breit klaffende Spalte, deren Querdurchmesser beiderseits $3 \mathrm{Mm}$. beträgt. (Fig. 4 und 5, Taf. VI u. VII.)

Ein ähnliches Vorkommen, aber nicht ganz so stark ausgeprägt, wurde noch an einem zweiten Schädel gefunden.

Bevor wir nun zu der Besprechung der praktischen Bedeutung der Fissura mastoideo-squamosa ibergehen, duirfte es angezeigt sein, uns vorher nach dem Vorkommen solcher physiologischer Oeffnungen in der äusseren Wandung des Sehläfebeines umzusehen, welchen entweder durch ibre Communication mit den lufthaltigen Räumen des Mittelohres dieselbe Bedeutung wie jenen zukommt, oder welche ein mehr anatomisches Interesse beanspruchen. Nähere Nachrichten über solche Liicken sind in der frïheren Literatur so spärlich vertreten, dass $W$ ernher ${ }^{1}$ ) sogar angibt, "es seien spontane Durchbohrungen der nach aussen gewendeten Wand des Zitzenfortsatzes nach anatomischen Untersuchungen nicht bekannt."

Hyrt ${ }^{2}$ ) sah allerdings nur zweimal solche Dehiscenzen, und zwar an der innern Wand der änssern, längeren und breiteren Lefze der Incisura mastoidea, in unmittelbarer Nähe der Spitze. Ausserdem erwähnt $\mathrm{Hyrtl}^{3}$ ) noch eines in seinem Besitze befindlichen, übrigens durchaus normalen Schläfebeins, an welchem hinter und über dem Meatus anditorius externus eine kreisrunde, 3 Linien weite Oeffnung in die Trommelhöhle führt.

Weitere hierher gehörige Fälle hat Zuckerkandl veröffentlicht:

1. Erwähnung eines Falles, wo fünf kleine Löcher der hinteren Wand des äusseren Gehörganges in die Warzenzellenräume führten. ${ }^{4}$ )

2. fand $Z$ u ckerkand 1 unter 200 Schläfebeinen vier Fälle, in welchen "Dehiscenzen durch die Zellenräume des sich an der Bildung des Warzenfortsatzes betheiligenden Schuppenstückes in den hintern Antheil der Paukenböhle führten, " 5 )

1) Wernher, Pneumatocele cranii. Deutsche Zeitschrift für Chirurgie. III, S. 381. 1873.

2) Hyrtl, Sitzungsberichte der kaiserlichen Academie d. Wissenschaften. XXX. Nr. 16. S. 278 und Handb. d. topographischen Anatomie. I. 1860. S. 258.

3) Hyrtl, Lehrbuch der Anatomie des Menschen.

4) Zu ckerkandl, Zur Entwicklung des äusseren Gehörgangs. M. f. O. 1873. Nr. 3. S. 34 .

5) Ebenda 1874. Nr. 7. S. 87. 
Ferner fand J. Gruber ${ }^{1}$ ) eine Dehiscenz in dem äusseren Blatte des horizontalen Stückes der Schuppe, welche die Paukenhöhle mit dem äusseren Gebörgang in Communication setzte.

$\mathrm{Sehwartze}{ }^{2}$ ) erwähnt, dass sich in der normalen einige (2-6) Mm. dieken Corticalis des Processus mastoideus zuweilen verdiunnte Stellen befinden, oder ange b o rne Ossificationslücken, von soleher Grösse, dass man die Spitze des kleinen Fingers hineinlegen kann.

Endlich beschreibt Bürkner ${ }^{3}$ ) zwei solche Fälle:

Fall 1. Dehiscenz der Warzenzellen nach aussen an der linken Seite eines erwachsenen, sehr dinnwwandigen Sehädels. „Die rareficirte Stelle erscheint als ein, zahlreiche feine Oeffnungen zwischen sich fassendes, zartes Balkengerüst; von den Oeffnungen fuhren nur wenige tief in den Knochen hinein.

Fall 2 betrifft einen 32 jährigen, männlichen Schädel mit colossalen Impressionen; " hier ist die Luicke der Pars squamosa beiderseits genau an der Stelle, an der Zuckerkandl diese Anomalie zum ersten Male beschreibt, nämlich an der Stelle jenes Grïbchens, das normal aiber dem obern Rande des Meatus acusticus externus osseus ïber der Spina supra meatum vorkommt."

Eine Spaltbildung besonderer Art wird noch von $\mathrm{Zucker}$ $\mathrm{kand}{ }^{4}$ ) beschrieben:

Fall 1. An demselben durehsetzt gerade unter dem Dache des Meatus acusticus`externus ein tiefer Spalt die ganze Länge der hinteren Wand des Gebörganges. Der Spalt ist von abgerundeten Rändern begrenzt und führt mit der lateralen Partie in" einige, im Hintergrunde der Fissur sichtbare Zellen des Warzenfortsatzes und mehr median in die Pankenhöhle; an der äussern Fläche des Felsenbeins endigt der Spalt in jener Furche, welche zuweilen in ausnehmender Tiefe vom Angulus parietalis und unter der Crista temporalis gegen den Gehörgang herabzieht. Die Spina supra meatum ist rudimentär vorhanden.

Fall 2 ist dem ersten sehr ähnlich, doch fehlt die Spina supra meatum ganz.

1) Gruber, Allg. Wiener med. Zeitung. 1872.

2) Schwartze, Pathologische Anatomie des Ohres (Handbuch der pathologischen Anatomie von Klebs). Berlin 1878. S. 109.

3) Bürkner, Kleine Beiträge zur normalen und pathologischen Anatomie des Gehörorgans. A. f. O. XIII. 1878, S. 189.

4) Zuckerkandl, Ueber eine typische Spaltbildung an der hinteren Wand des äussern Gehörgangs, M. f. O. 1878. S. 46. 
Fall 3. Der Spalt greift an einer. Stelle auch auf die obere Gehörgangswand über. Er erweitert sich nach innen birnförmig, reicht etwa bis zur Grenze zwischen dem äussern und mittlern Drittel des Gehörgangs und führt in einige, im Hintergrunde des Spaltes eröffnete, obere Zellen des Processus mastoideus hinein. Die Spina supra meatum fehlt. -

Allen diesen Defecten ist gemeinschaftlich: die Oertlichkeit, die Passage durch das Grübchen oberhalb des Gehörganges, wodurch die Spina supra meatum entweder gänzlich ausfiel, oder sehr reducirt erseheint, und schliesslich die Eröffnung der pneumatischen Höhlen des Schläfebeins (des Warzenfortsatzes und in zwei Fällen auch die der Paukenhöhle).

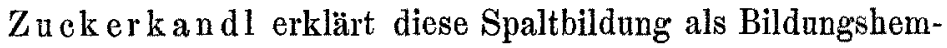
mung: "Wir wissen, dass die Schuppe des Schläfebeines einen Fortsatz trägt, der sich an der Bildung des Warzenfortsatzes betheiligt. Die Anlage dieses Fortsatzes ist nun vor dem zweiten intrauterinen Lebensmonat ein selbständiges Knochenplättehen, welches alsbald mit der Schuppe verwächst und von den Franzosen l'épitympanique genannt wird. Untersucht man nun die Stelle, wo die beiden angeführten Knochen aneinanderstossen, so entspricht sie vollständig der Oertlichkeit der von uns beschriebenen Spalten und ich möchte daher für die' letztern eine theilweise Persistenz der Fuge zwischen Schläfebeinschuppe und Os epitympanicum annehmen."

Ich habe diese entwicklungsgeschichtliche Angabe, welche Zuekerkandl ron Rambaud und Renault I) entnommen hat, nicht nachprïfen können, da mir Embryonen aus so früher $\mathrm{Pe}-$ riode nicht zu Gebote standen. Bei wenig älteren war dieser Fortsatz immer schon mit dem vorderen Theil der Schuppe vereinigt und zwischen Linea temporalis und dem Fortsatze entwickelte sich dann erst die Lamina externa.

Diejenigen Fälle von Lücken in der Aussenwand des Schläfebeins, welche ich selbst antraf, fanden sich in der grossen Mehrzahl in der Lamina externa des hintern Schuppentheils, welche die äussere Wand des Antrum mastoideum bildet. Ehe ich daher zur Beschreibung jener Fälle übergehe, gestatte ich mir, eine Darstellung der normalen anatomisehen Verhältnisse dieser Platte zu geben.

Von der nach oben und binten sich aufbiegenden Linea 1864.

1) A. Rambaud et Ch. Renault, Origine et développement des os. Paris 
temporalis zweigt sich ungefähr nach dem ersten Drittheil ihres Verlaufs auf der Schuppe eine nach rorn und unten concave Linie $a b$, welche zum hinteren Rande des Processus tympanicus squamae verlänft, und so den auch bei dem Neugebornen schon mässig eingebogenen horizontalen Theil der Schuppe von dem verticalen Theile trennt.

In dem Anfangstheile dieses nach abwärts steigenden Schenkels der Linea temporalis finden wir hänfig bereits beim Neugebornen eine circumscripte Erhöhung oder Rauhigkeit: die Anlage der Spina supra meatum (Henle-Bezold); oder auch die Andeutung des Grübchens, welches nach hinten und oben von der Spina supra meatum liegt, und in Ermangelung der letzteren uns den Beginn des Meatus auditorius externus anzeigt.

Bei der Bedeutung, welche die Spina supra meatum durch ihre Lage im Verhältniss zu der des Antrum mastoideum in operativer Hinsicht hat ${ }^{1}$ ), war es für mich von Interesse, die Hâufigkeit des Vorkommens derselben zu prüfen. In der folgenden Zusammenstellung habe ich das Grübchen über der Spina auch in solchen Fällen als vorhandene Spina mitgerechnet, wenn letztere nicht vorhanden war, da ersteres in praktischer Beziehung dieselben Dienste leistet. Bei Heranwachsenden ergaben sich folgende Verbältnisse:

\begin{tabular}{|rl|c|c|c|c|}
\hline & & $\begin{array}{c}\text { rechts und } \\
\text { links vor- } \\
\text { handen } \\
\text { Proc. }\end{array}$ & $\begin{array}{c}\text { rechts vor- } \\
\text { banden, } \\
\text { links nicht } \\
\text { Proc. }\end{array}$ & $\begin{array}{c}\text { links vor- } \\
\text { handen, } \\
\text { rechts nicht } \\
\text { Proc. }\end{array}$ & $\begin{array}{c}\text { beiderseits } \\
\text { nicht }\end{array}$ \\
Proc. \\
\hline \hline
\end{tabular}

Bei der Gesammtsumme der 174 untersuchten Schädel sind die Verhältnisse:

1) Bezold, Die Perforation des Warzenfortsatzes rom anatomischen Standpunkt aus. M. f. $0.1873 \mathrm{Nr} .11 .1874 \mathrm{Nr} .1$ und 2, sowie Aerztliches Intelligenzblatt 1874. S. 211. 


$\begin{array}{cccc}\begin{array}{c}\text { rechts und links } \\ \text { vorhanden }\end{array} & \begin{array}{c}\text { rechts worhanden } \\ \text { links nicht }\end{array} & \begin{array}{c}\text { links vorhanden } \\ \text { rechts nicht }\end{array} & \begin{array}{c}\text { beiderseits } \\ \text { nicht }\end{array} \\ \text { 82,2 Proc. } & \text { 2,9 Proc. } & 2,9 \text { Proc. } & 12,0 \text { Proc. }\end{array}$

dagegen bei 100 Erwachsenen:
87 Proc.
3 Proc.
6 Proc.
4 Proc.

Es seheint aus diesen Zahlen hervorzugehen, dass die Spina supra meatum sich später nicht mehr entwickelt, wenn sie nicht schon in der ersten Zeit des Lebens in der Anlage vorhanden war.

Dieser absteigende Schenkel der Linea temporalis, resp. die Spina supra meatum ist es, welcher mit dem Anfangstheile der Linea temporalis die eigentliche Grenze zwischen horizontalem und verticalem Theil der Schuppe bildet, denn von hier aus beginnt erst die entschiedene Einwärtsbiegung des untern Schuppentheils, während der hinter und utber dieser Linie befindliche Sohuppentheil stets die verticale Stellung beibehält. ${ }^{1}$ )

Medianwärts von dem nach hinten offenen Winkel, welcher durch die Vereinigung des auf- und des absteigenden Schenkels der Linea temporalis gebildet wird, liegt das vordere Ende des Antrum squamosum. Es wird also die Schuppenplatte, welche beim Neugebornen von aussen das Antrum mastoideum deckt, nach oben von einer Linie begrenzt, welche rom Scheitel dieses Winkels zu dem frither beschriebenen oberen Ende des Antrum führt; nach unten von dem absteigenden Schenkel der Linea temporalis; resp. dem hintern obern Rande des Porus acusticus externus, während nach hinten der mittlere Theil der Fissura mastoideo-squamosa die Begrenzung bildet. Es kommt übrigens schon in der frühesten Lebenszeit vor, auch schon ehe überhaupt die Zellenbildung um das Antrum mastoideum beginnt, dass das Antrum squamosum sich nach vorn oben bis unter die Linea temporalis oder sogar noch etwas darüber hinaus erstreckt.

Bei der Weiterentwicklung ändert sich das Verhältniss des Antrum mastoideum zu dieser Platte insofern, als letatere immer weiter nach aussen, hinten und unten rückt. Während daher beim Neugebornen der mittlere Theil der Fissura mastoideosquamosa direct in das, Antrum fübrt, liegt schon nach den ersten Lebensjahren die hintere Wand des Antrum nach vorn und oben ron diesem Theile.

Diese äussere Decke des Antrum, resp. der Schuppenzellen des Erwachsenen ist bei vielen Kinderschläfebeinen aus der frühesten Lebenszeit sehr dïnn und durchscheinend, ja in vielen

1) Vgl. Luschka, Die Anatomie des menschlichen Körpers. Tübingen 1867. III. 2. S. 88. 
Fällen ist das Gewebe derselben von zahlreichen Lïcken durchbrochen, auch an solchen Schädeln, welche keine Spur von Rhachitis zeigen. (Fig. 6. Taf. VI u. VII.)

Dieser Zustand scheint ofter zu persistiren, wenigstens fand ich an drei Schädeln von älteren Kindern gerade in diesem Theile der Schuppe zahlreiche, scharf begrenzte Lïcken, welche in das Innere des Warzenfortsatzes oder zur vorderen Partie der Schuppenzellen führen. Am ausgeprägtesten zeigten sich dieselben an beiden Schläfebeinen eines $3 \frac{1}{1} 2$ Jahre alten Knaben.

Auf der rechten Seite liegt vor der noch deutlich erkennbaren Sutura mastoideo-squamosa eine Gruppe von 14 Löchern, die nach oben bis an den untern Rand der Schläfenlinie reicht (Fig. 7. Taf. VI u. VII), in Form einer im Querdurehmesser durchschnittenen Ellipse mit der Oeffnung nach unten vorn. Der Querdurchmesser beträgt 7,5 , die Höhe $6 \mathrm{Mm}$. Das oberste grösste dieser Löcher hat einen Längsdurchmesser von $2 \mathrm{Mm}$. Die Borste dringt durch einzelne dieser Löcher über $1 \mathrm{Cm}$. tief ein. Der innere von diesen grösseren Löchern umgebene Raum hat durch kleinere Löcher ein siebförmiges Ansehen. Vor dieser Gruppe liegt eine kleinere von 4 Löchern dicht hinter und über der Spina supra meatum.

Auf der linken Seite sind die Verhältnisse ähnlich, doch reicht die hintere Gruppe bis zur Fissura mastoideo-squamosa nach rückwärts, während die vordere Gruppe sich bis zum Anfangstheile der Linea temporalis fortsetzt.

Bei dem zweiten Schädel, welcher einem 3 jährigen Kinde angehörte, sind diese Lücken in ähnlichen Verbältnissen vorhanden, jedoch in geringerer Anzahl.

Der dritte Fall fand sich am Schädel eines 6 jährigen Kindes: Etwa $5 \mathrm{Mm}$. hinter beiden Spinae, in gleicher Höhe mit denselben, beginnt eine Einsenkung der Schuppe, welche rechts eine Höhe von $4 \mathrm{Mm}$., links eine solche von $5 \mathrm{Mm}$. hat, and rechts von grösseren, links von kleineren Löchern durchsetzt ist.

Eine einzelne Lïcke fand ich am rechten Schläfebein eines 10 jährigen Knaben. Dieselbe liegt gerade nach hinten von der Spina supra meatum, und hat eine Länge von $3 \mathrm{Mm}$., eine Breite ron $1 \mathrm{Mm}$. Auch fand ich eine solche an dem Schädel eines 17 jährigen Jtinglings (Fig. 8. Taf. VI u. VII. In gleicher Höhe mit der Spina supra meatum, $5 \mathrm{Mm}$. hinter derselben, befindet sich eine kreisrunde Grube von $6 \mathrm{Mm}$. Durchmesser, deren Boden gegen das untere Ende hin durch eine Oeffnung von $2 \mathrm{Mm}$. 
Höhe und 2,3 Mm. Breite durchsetzt ist. Die Sonde dringt dureh letztere nahezu $1 \mathrm{Cm}$. tief ein.

Ein selteneres Vorkommen von Verbindung der äussern Wandung mit den Warzenzellen fand ich an dem rechten Schläfebein eines etwa 2 jährigen Kindes. Der Knochen ist sehr leicht und dünn, Sehuppe und hintere Partie des Warzentheils sind durehscheinender als gewöhnlich. Der Boden der Paukenhöhle ist von dem Sinus jugularis kaum durch eine vielfach durchlöcherte Knochenplatte getrennt, und von der untern Wand des Canalis caroticus existirt nur eine schmale Knochenspange am medialen Ende desselben. Es findet sich nun an dem horizontalen Theile der Schuppe, etwas oberhalb der Mitte zwisehen Spina supra meatum und Margo tympanieus squamae eine kreisrunde Oeffnung von $2 \mathrm{Mm}$. Durchmesser, welche aber nicht wie in dem von Gruber erwähnten Falle, eine directe Verbindung der äussern Gehörgangswandung mit der Trommelhöhle herstellt. Die Oeffnung futhrt vielmehr in eine geräumige Knoehenzelle, welche nach oben zwei kleinere, nach hinten einen grösseren Ausgang hat. Die beiden ersteren führen zu den obern vorderen Schuppenzellen, während der hintere Ausgang in das Antrum mastoideum fübrt.

An circa zweihundert Schädeln Erwachsener, die ich auf solche Lücken der Lamina externa untersucht habe, fand ich dieselben nur einmal und zwar an dem Schädel eines, wie es scheint, im mittleren Lebensalter verstorbenen Individuums. Die Lage dieser Lücken zeigt sich in solcher Uebereinstimmung mit den in Fig. 6-8 (Taf. VI u. VII) gezeichneten, dass man wohl annehmen kann, dass sie auch derselben Ursache ihre Entstehung verdanken, nämlich angeboren sind.

Dicht nach hinten und oben von der Spina supra meatum befinden sich, mit ibrem vordern untern Rande derselben annähernd parallel verlaufend (Fig. 9, Taf. VI u. VII), zwei dureh eine schmale Knochenbrïcke getrennte viereckige Oeffnungen, die zusammen eine Breite von 4,5 Mm. besitzen. Die Höhe derselben beträgt 2,5 Mm. $3 \mathrm{Mm}$. über der hintern derselben liegt eine ähnliche Oeffnung von nahezu derselben Grösse, 5,5 Mm. unterhalb der Temporallinie. Die Sonde dringt durch die obere Oeffnung über $1 \mathrm{Cm}$. tief ein, durch die beiden unteren etwas weniger tief.

In dem horizontalen Theile der Schuppe findet man bisweilen noch hinter dem Processus articularis posterior eine Oeffnung, 
„das Foramen jugulare spurium, welches aber auch nicht selten seine Lage neben der hintern Wurzel des Jochbogens hat, stets aber als Miundung eines Sulcus petro-squamosus, d. h. des ursprünglichen Sinus transversus zu betrachten ist." 1)

Das Vorhandensein dieses Sulcus petro-squamosus sowie des Foramen jugulare spurium ist aus der Entwicklungsgeschichte zu erklären. Kölliker ${ }^{2}$ ) sagt hierüber: „Die Venae jugulares anlangend, so liegen ihre ersten Zweige in der Schädelhöhle und fliessen jederseits in einem Gefässe zusammen, das als Anfang des Stammes angesehen werden kann und später als Sinus transversus erscheint. Dieses Gefäss verlässt jedoch die Schädelhöhle nicht durch ein Foramen jugulare, sondern durch eine besondere, vor der Ohrgegend gelegene Oeffnung, welche, wie Luschka gezeigt hat, auch am ausgebildeten knöchernen Schädel noch erhalten sein kann und dann am Schläfebeine über dem Kiefergelenke liegt. Später verschliesst sich diese Oeffnung und wird das Blut der Schädelhöhle durch eine nahe am Ductus Cuvieri aus dem untersten Ende der primitiven Jugularis hervorgesprosste Jugularis interna abgeftuhrt, so dass dann die erstere als Jugularis externa erscheint."

Zuckerkandl ${ }^{3}$ ) fand den Sinus petroso - squamosus unter 280 Schädeln 22 mal, ein Foramen jugulare spurium 3 mal.

An einem rechten Schläfebeine (eines etwa $1 \frac{1}{1 / 2}$ jährigen Kindes) meiner Sammlung verläuft der Sulcus petro-squamosus von der Incisura parietalis dicht am Rande des Tegmen tympani in der Schuppe nach vor- und abwärts bis etwa zum vordern Drittel der Fissura petro-squamosa. An dieser Stelle ist die innere Lamelle der Schuppe durchbrochen und führen von dieser Stelle zwei Kanäle nach aussen, von denen der hintere untere gerade iiber dem vordern obern Ende des Paukentheils hinter dem Processus articularis posterior mündet, während der vordere obere in der Falte zwischen Jochbogen und Schuppe die Oberfläche der Schuppe erreicht. Eine Verbindung dieses Suleus petrosquamosus mit dem Sulcus sigmoideus habe ich in diesem Falle nicht nachweisen können.

Von den im Vorhergehenden beschriebenen Lücken der äussern

1) Laschka 1. c.

2) Kölliker, Entwicklungsgeschichte des Menschen und der höheren Thiere. Leipzig 1879. S. 928.

3) Zuckerkandl, Beitrag zur Anatomie des Schläfebeins. M. f. 0.1873. Nr. 9. 
Schläfebeinwand haben in praktischer Beziehung diejenigen die grösste Wichtigkeit, welche zu den pneumatischen Räumen des Mittelohres fuibren. Es sind dies zuerst die Fissura mastoideosquamosa oder die beim Erwachsenen von ihr uiberbleibenden Spalte und Löcher; jedenfalls von ebenso grosser Bedeutung sind die Liieken der Lamina externa. Durch die gegebene Reihe vom Vorkommen derselben in den verschiedensten Lebensaltern wird nun wohl auch die Angabe ron Schwartze bestätigt, dass diese Ossificationslitcen angeborne seien.

Beide Arten von angebornen Oeffnungen sind wohl geeignet, uns sowohl das mitunter überraschende Uebergreifen von krankhaften Processen des Mittelohres auf die äussere Wand des Processus mastoideus, als auch die spontane Entstehung von Emphysem sowie der sogenannten Pneumatocele capitis (supramastoidea Wernher) zu erklären.

Die Ueberleitung von Entzïndungen durch die Fissura mastoideo-squamosa wird am ersten im frihesten Kindesalter stattfinden, wo die Fissur noch regelmässig vollkommen vorhanden ist und direct in das Antrum mastoideum führt.

Bezold ${ }^{1}$ ) sagt hieriber: "Nachdem bei den betreffenden Kindern längere Zeit, Monate oder Jahre eine chronische eitrige Paukenhöhlenentzïndung bestanden hat, wird einmal plötzlich die Gegend des Warzenfortsatzes direct hinter der Muschel auf Druck empfindlich. Rasch gesellen sich dazu Röthung, Schwellung, sowie mässiges Fieber, und die Muschel wird in der charakteristischen Weise abgehoben, dass sie zur Seitenfläche des Kopfes mehr senkrecht steht und ihre hintere Ansatzlinie über die Höhe der Geschwulst herabläuft. Wo diese Erscheinungen auftreten, sind wir zu der Annahme berechtigt, dass eine grössere Ansammlung von Secret im Antrum mastoideum und den Warzenzellen einen Ausweg durch die Fissura mastoideo-squamosa nach aussen hinter das Periost der Aussenfläche-der Pars mastoidea gefunden hat.- Da die Lage der Fissura mastoideo-squamosa der hinteren Ansatzlinie der Muschel entspricht oder etwas vor derselben parallel mit ihr herabläuft, so wird eine aus den restirenden Löchern und Spalten dieser Fissur hervorkommende Eiteransammlung sich wie ein Keil zwischen die Knochenfläche und die nach vorn fest fixirte Muschel drängen und die letztere mehr oder weniger rechtwinklig zum Kopf stellen."

1) Bezold, Erkrankungen des Warzentheils. A. f. 0. XIII. 1877. S. 51. 
Im späteren Alter werden die Fissura mastoideo-squamosa und die Lücken der Lamina externa sich wohl gleichmässig an solcher Ueberleitung betheiligen, da dann die Fissura mastoide0squamosa aufgehört hat, der bequemste Weg für solche Vorgänge zu sein. Es kommt übrigens beim Erwachsenen Periostitis der Warzenfortsatzgegend tiberhaupt seltener vor, als bei Kindern, wohl auch schon wegen der grössern Entfernung der äussern Wand von dem ursprünglichen Erkrankungsherde.

Wenn wir nun die Entstehung der Emphyseme an der Warzenfortsatzgegend und der Pneumatocele cranii supramastoidea betrachten, so musste allerdings, ehe das Vorkommen von an geborne n Ossificationslüeken in dieser Gegend bekannt war, die Erklärung der Genese dieser Luftansammlungen die grössten Schwierigkeiten bieten. So sagt Heineke ${ }^{1}$ ): "Doch sind nur zwei Möglichkeiten vorhanden; entweder der Knochen ist allmählich atrophirt, oder er ist durch Caries sicca aufgezehrt. Knochenatrophie bis zur Perforation an den dünnern Stellen ist bekanntlich am Schädel älterer Lente nicht selten. Die äussere Wand der Zellen des Processus mastoideus ist oft ausserordentlich diunn (Toynbee, Huschke), bis zu 1/10"'. Die Mehrzahl der von Pneumatocele Befallenen stand jedoch im mittleren Lebensalter, nur einer war 57 Jahre alt. Eine Caries sicca, welche im Innern des Processus mastoideus beginnt, kann vermuthlich symptomlos verlaufen."

Hyrt ${ }^{2}$ ) spricht sich noch energischer gegen die Entstehung: solcher Lücken durch Altersatrophie aus: "Die spontane Eröffnung der Trommelhöhlen oder der Zitzenzellen kann keine Altersmetamorphose sein, da sie auch an Schädeln jüngerer Individuen vorkommt, obwohl in geringerem Maasse.... selbst an solchen Schädeln, deren Knochen auffallend dick und stark sind, habe ich sie gesehen. An Atrophie als ursächliches Moment ist somit nicht zu denken."

Hyrtl sucht deshalb die Entstehung dieser Licken durch zwei Möglichkeiten zu erklären:

1. bei Frauen durch den gesteigerten Verbrauch von Knochenerde wäbrend der Gravidität.

2. durch allmähliche Verdünnung der Knochen in Folge von häufig excessiv gesteigertem Luftdrucke in den pneumatisehen

1) Heineke, Chirurgische Krankheiten des Kopfes. Pitha und Billroth. III. 1. Abtheilung.

2) 1. c. (Sitzungsberichte.) S. 279. 
Räumen des Mittelohres. "Wenn der Druck strotzender Venen Knochenwände so verdünnen kann, dass sie endlich sich öffnen, wie man an den den Bulbus der Jugularvene nach oben und hinten umgebenden Knochenflächen . . . . sehen kann, wènn man ferner die Ausbiegungen in Anschlag bringt, welche Knochenebenen durch Druck nachbarlicher luft- oder flïssigkeithaltender Organe unter gewissen Umständen erfahren, so wird auch zugegeben werden können, dass ein so hoher Grad ron Verdichtung der Luft in der Rachen-, Pauken- und Zitzenhöhle, wie er den schmetternden Explosionen solchen Schnenzens vorausgeht, auf die Ausweitung solcher Höhlen, und sofern sie knochenumfangen sind, auf Distention und endlichen Durchbruch derselben hinwirken kann."

Auch Wernhe ${ }^{1}$ ) glaubt, dass der verdünnte Knochen durch starke Spannung der Luft, beim Sehneuzen, Niesen, bei der Anwendung der Luftdouche, plötzlich durchbrochen werden könne, ohne dass eine verschwärende Entzïndung oder ein deutliches Trauma mitzuwirken braucht. Dieselben Ursachen können dann die Luft unter das Pericranium treiben.

Als Gelegenheitsursachen der in der Literatur verzeichneten Fälle ${ }^{2}$ ) von spontan entstandener Pneumatocele werden angegeben:

1. Diätfehler (Erbrechen?), Fall von Lecat.

2. Valsalva'scher Versuch, Fall von Schmidt.

3. Heftiges Niesen, Fall von Wernher.

4. keine: Fall von Hunter (Lloyd).

$$
\begin{array}{ll}
n & \text { Pinet. } \\
& \quad \text { Balassa. } \\
& \quad \text { Denonvilliers. } \\
& \quad \text { Fleury. } \\
& \quad \text { Voisin. }
\end{array}
$$

Der Fall von Vianna gehört wohl auch zu den ohne bekannte Gelegenheitsursache entstandenen Pneumatocelen, da ein unbedeutender Stich in den linken Gehörgang, welchen sich der Patient mehrere Monate vorher zugefügt hatte, wohl kaum als solche betrachtet werden kann.

Die gemeinschaftlichen Symptome der Pneumatocele cranii

1) 1. c. S. 398 .

2) Die Casuistik findet sich bei Heineke l. c. und Wernher l. c., s. auch Schmidt, Ueber emphysematöse Geschwülste am Schädel. I. - D. Würzburg 1871 . 
supramastoidea sind vorwiegend: die weich elastische Beschaffenheit der Geschwulst, ihre Schmerzlosigkeit, der Mangel an localer Hitze und Röthung, der tympanitische Percussionsschall. Ferner waren die meisten derselben ganz oder theilweise reponirbar, wobei Blasegeräusch oder Knistern gehört wurde. Die Communication mit dem Mittelohre konnte in den Fällen von Wernher, Balassa, Denonvilliers und Schmidt dadurch nachgewiesen werden, dass bei dem Valsalva'schen Versuche oder bei Niesen und Schneuzen die Grösse des Tumors zunahm. Dass durch das Austreten der Luft das Pericranium in die Höhe gehoben war, ist wohl auch durch den Umstand bewiesen, dass in allen Fällen bis auf einen, Knochenneubildung vorhanden war. In dem von Schmidt beschriebenen Falle war nämlich die Heilung schon nach acht Tagen unter Anwendung eines leichten Compressionsverbandes eingetreten.

Die beiden Fälle, wèlehe zur Section kamen, ergaben in Bezug auf die anatomischen Veränderungen ein negatives Resultat. In dem Falle von Lecat lieferte die Section über die Quelle der Luft keinen Aufschluss; in dem Falle von Fleury wurde zwar eine Oeffinung am Zitzenfortsatz gefunden, doch konnte deren Communication mit dem Mittelohre nicht nachgewiesen werden.

In dem Falle von Balassa dagegen, bei welchem auch die Communication zwischen den pneumatischen Höhlen und der Luftgeschwulst eine ziemlich freie war, sah man nach der Incision deutlich mehrere Oeffnungen, welche in den Processus mastoideus hineinführten.

Was nun die Entstehungsweise der spontanen Pneumatocele betrifft, so bin ich der Ansicht, dass dieselbe in der That durch oft wiederholte Zunahme des Luftdruckes im Mittelohre entsteht. Doch werden sich hierzu wohl nur in seltenen Fällen die Reste der Fissura mastoideo-squamosa eignen, da dieselben meist nur enge Gefässkanäle darstellen. Dagegen sind die angebornen Ossificationslïcken der Lamina externa wohl geeignet, uns das Entstehen der Pneumatocele zu erklären. Die dünne Schleimhaut der pneumatischen Zellen wird keinen erheblichen Widerstand leisten können; das die Lïcke selbst schliessende Bindegewebe wird durch fortgesetzte Insulte so lange gedehnt und gezerrt, bis es endlich an irgend einer Stelle nachgibt, und dann die Luft unter das Pericranium ausweichen kann. 


\section{Zur Anatomie des Felsen - Warzentheils.}

Nach der Untersuchung von Vrolik ${ }^{1}$ ) entsteht die Pars mastoidea aus zwei selbständigen Knochenpunkten, einem hintern und einem vordern, während Joseph (1. c.) überhaupt das Vorkommen eines gesonderten Knochenkernes in der Pars mastoidea in Abrede stellt, und dieselbe nur als äussere Fläche des Felsentheils, als Planum mastoideum gelten lassen will. Ich muss die Angabe Vrolik's für die richtige halten, da ich den hintern Theil der Pars mastoidea bei zwei Embryonen von $26 \mathrm{Cm}$. Länge noch sowohl vom Felsentheile als anch dem vordern Theile der Pars mastoidea getrennt fand. Zur Bekräftigung dieser Ansicht dient auch eine Abnormität, welche ich an dem Schädel eines Erwachsenen in der Wiener anatomischen Sammlung fand.

Dieser Schädel ist von normaler Schwere (Fig. 10 und 11, Taf. VI u. VII), die Nähte sind im Allgemeinen gut erhalten, bis auf die Sutura occipito-mastoidea, von welcher sich beiderseits keine Spur mehr findet. Dagegen verläuft rechts, $8 \mathrm{Mm}$. hinter der Incisura parietalis beginnend, eine Sutur, welche anfangs direct nach abwärts verlaufend, sich dann nach vorn wendet. In diesem zweiten Theile verläut die Naht im Grunde der Incisura mastoidea, der Längsrichtung derselben folgend, so dass der Processus mastoidens mit der äussern Lefze der Incisur vollständig von der hintern Partie des Warzentheils mit der innern Lefze der Incisur abgetrennt ist. Ihr Ende findet die Sutur dicht hinter dem Foramen stylo-mastoideum durch die Verwachsung des Processus jugularis mit der hintern Scheidenwand des Processus styloideus.

An der Innenfläche des Schädels verlüuft die Sutur anfangs genan am hintern Rande des Suleus transversus, wendet sich dann nach vorn, letztern durehschneidend. Am vordern Rande des Sulcus angekommen, hört sie ebenfalls am Processus jugularis auf. Die Naht ist am obern Ende ziemlich stark gezackt, am untern Ende während des Querverlaufs durch den Sulcus transversus etwas weniger, in der Mitte des Verlaufs ist es mehr Apposition. Es befindet sich also die innere Wand der Incisura mastoidea vollständig anf dem Theile der Pars mastoidea, welche mit dem Hinterhauptsbeine knöchern vereinigt ist.

1) Vrolik, A. J., Die Verknöcherung des Schläfenbeins der Säugethiere. Niederländisches Archiv für Zoologie. I. 3, 1873. S. 296. Vergl. die dazu gehörige Tafel XXII. Fig. 48. 
Ein Foramen mastoideum ist an diesem Schädel nur links vorhanden, wo es in dem dieser hintern Partie des Warzentheils entsprechenden Theile verläuft. Eine weitere Abnormität zeigen beide Felsentheile darin, dass der äussere obere Theil der hintern obern Wand so stark eingesunken ist, dass beiderseits der Verlauf des hintern halbcirkelförmigen Verticalkanals in seinem obern and absteigenden Theile deutlich hervortritt.

Ueber das Wachsthum des Processus mastoideus habe ich nähere Angaben in der Literatur nicht gefunden. Die Anlage desselben sitzt beim Neugebornen als schwammige Haube dem compakten Knochenwulste auf, welcher den Canalis semicircularis externus umschliesst. Der Processus tympanicus squamae, welcher später vollkommen mit dem Warzentheile verschmilzt, ist noch durch den untern Theil der Fissura mastoideo-squamosa nach vorn, meist auch nach unten, bis auf die zur Zeit der Geburt meist schon verschmolzene Spitze, von ihm getrennt. Der vordere untere Rand des Warzenantheils ist nicht selten rertieft, so dass hierdurch ein breiterer Spalt zwischen Schuppen- und Warzenantheil des Processus mastoideus entsteht, welcher auch noch in späterer Zeit persistiren, oder in seltenen Fällen sich noch verbreitern kann. (Fig. 4 und 5, Taf. VI u. VII.)

Bei der weitern Entwicklung dehnt sich der Processus mastoideus zunächst nach aussen und hinten aus, später erst beginnt auch das Wachsthum nach unten. Gleichzeitig wird das Bild durch das nach auswärts Wachsen der Linea temporalis verändert, wodurch die obere Wand des Gehörganges nach aussen verlängert wird, da der Margo tympanicus squamae in dem früheren Verhältnisse zur Paukenhöhle bleibt. Dadurch entsteht die mehr horizontale Lage der obern Gehörgangswand, wäbrend die Verticaldistanz zwischen der Grenzlinie des horizontalen und verticalen Schuppentheils einerseits und Margo tympanicus andererseits sich nicht wesentlich ändert. Durch dieses gleichmässige nach auswärts Wachsen des Sehuppen- und Warzentheils wird die Entfernung der äussern Wand von dem Mittelohre immer grösser.

Der Theil der Schuppe, welcher beim Neugebornen die äussere Deckplatte des Antrum mastoideum bildet, wächst zu gleicher Zeit nach hinten und abwärts fort, so dass die Spuren des von dieser Platte nach vorn begrenzten Theils der Fissura mastoideosquamosa schliesslich weit nach hinten, unten und aussen vom Antrum mastoideum gefunden werden, und dieser Schuppentheil einen beträchtlichen Theil des Processus mastoideus uiberkleidet. 
Mitunter ist derselbe bis zu zwei Dritteln oder selbst mehr an der Bildung der äussern Wand des Zitzenfortsatzes betheiligt. Im Uebrigen reicht bei Erwachsenen der Schuppenantheil wobl nie bis zur Spitze des Processus mastoideus herab, sondern es wendet sich die ursprünglich hintere Kante nach vorn, etwa in Höhe des unteren Randes des Porus acusticus externus oder wenig tiefer, so dass also der Warzenantheil nach aussen von dem Processus tympanieus squamae iiber den letztern herabwächst.

Die Höhe des Processus mastoideus nimmt in folgenden Verhältnissen zu. Es wurde die Linie gemessen, welche senkrecht von der Spitze auf die Verlängerung des hintern Theils des obern Jochbogenrandes fällt. Letztere sehneidet den hintern Schuppenrand unter der Linea temporalis ungefähr in der Höhe des obern Endes des Antrum mastoideum. Zur Vergleichung füge ich die Entfernung des Durchschneidungspunktes beider Linien ron dem Foramen stylo-mastoideum bei.

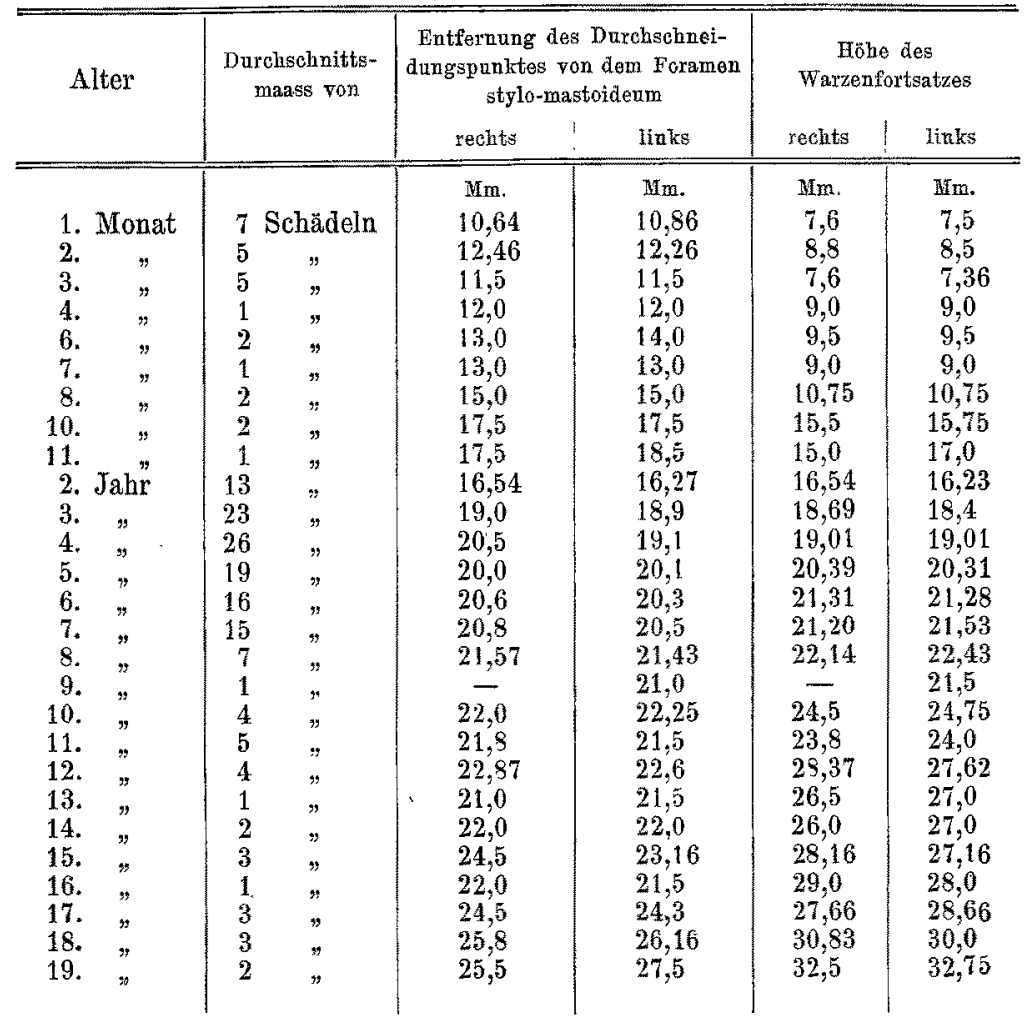


Aus vorstehender Tabelle geht hervor, dass die Entfernung des obern Messpunktes rom Foramen stylo-mastoideum bis zum fünften Jahre grösser ist, als die Höhe des Processus mastoideus. Eine Andeutung der Incisura mastoidea fand sich zuerst im sechsten Monat, ein Herabragen der Spitze des Processus mastoideus über die Incisura mastoidea zuerst im 10. Monat.

Die Incisura parietalis ist zu Messungen nicht zu verwerthen, da ihr Stand wegen der (bei Beschreibung der Fissura mastoideosquamosa des Neugeborenen) angegebenen Unregelmässigkeiten ein $\mathrm{zu}$ wechselnder ist. Mitunter ist die Incisura parietalis auch schon in sehr fribem Alter nicht mehr aufzufinden, da das Scheitelbein an dieser Stelle knöchern mit Warzentheil und Schuppe vereinigt ist. Vier Fälle derartiger Verknöcherung betrafen sämmtlich Knaben:

1. rechts, Alter $23 / 4$ Jahr.

2. links $\quad " 3^{1 / 4}$ Jahr.

3. links $\quad, 5 \frac{1 / 2}{1}$ Jahr.

4. beiderseits " 6 Jahre.

Ein gutes Maass dagegen, um uns das Wachsthum des Processus mastoideus nach hinten und unten za vergegenwärtigen, bietet die Entfernung des Foramen stylo-mastoideum von der Spitze des Fortsatzes, obgleich die untere Oeffnung des Canalis facialis beim Erwachsenen auch tiefer liegt als beim Neugeborenen. Während beim Neugeborenen das Foramen stylo-mastoideum gerade unter der Anlage des Processus mastoideus oder sogar nach hinten und unten von derselben liegt, fällt dasselbe beim Erwachsenen fast vor denselben. Bis zum 10. Monat, also so lange der Warzenfortsatz noch nicht herabwächst, bleibt die Entfernung nahezu die gleiche, während sie von da ab stetig zunimmt.

Die Durchschnittszahlen fïr die Entfernung vom Foramen stylo-mastoideum bis zur Spitze des Processus mastoidens betragen:

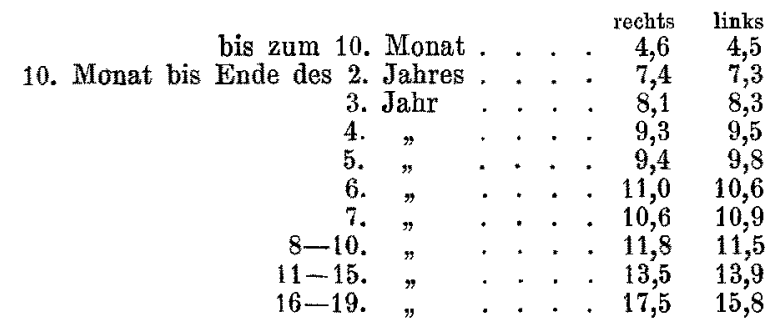


Wenn wir nunmehr das Verhältniss der Aussenwand des Schläfebeins zu der Lage des Antrum mastoide um betrachten, so finden wir bei dem Neugebornen folgende Anhaltspunkte:

1. den Scheitel des Winkels, welchen die nach hinten auseinanderweichenden Schenkel der Linea temporalis bilden, da die Projection desselben das vordere Ende des Antrum squamosum trifft.

2. den Einsehnitt zwischen oberem und mittlerem Drittel der Fissura mastoideo-squamosa, da derselbe den obersten Punkt des Antrum mastoideum bezeichnet.

3. das mittlere Drittel der Fissur selbst, da dasselbe direct in das Antrum führt.

4. die Anlage des zukïnftigen Warzenfortsatzes, da dieselbe die nach aussen gerichtete Verlängerung des Knochenwulstes bildet, welcher den äussern halbcirkelförmigen Kanal umschliesst. Ueber diesem Knochenwulste befindet sich aber bekanntlich die sogenannte Uebergangsstelle (aditus ad antrum).

5. die untere Grenze des Antrum wird durch den Verlauf des absteigenden Schenkels der Linea temporalis bezeichnet (Spina supra meatum).

6. den Margo tympanicus squamae, welcher nach vorn, unten und aussen vom Antrum liegt.

7. den hintern Rand des Annulus tympanicus, welcher gerade nach unten von dem Antrum liegt.

Alle diese Anhaltspnnkte, mit Ausnahme des Margo tympanicus squamae, werden zunächst durch das nach aussen gerichtete Wachsthum der äussern Wand des Schläfebeins und die daraus resultirende Dickenzunahme derselben nach auswärts vom. Antrum mastoideum entfernt.

In Bezug auf die frontalen Durchschnittsverhältnisse, durch das nach hinten und unten gerichtete Wachsthum, werden eine wesentlich andere Stellung zum Antrum erhalten:

1. die Fissura mastoideo-squamosa, indem die Projection derselben hinter das Antrum mastoideum fallen wird.

2. der Processus mastoideus. Das Wachsthum desselben verändert seine relative Lage zum Antrum bedeutend. Während beim Neugebornen eine Frontalebene, welche man durch die hintere Wand beider Warzenhöblen gelegt denkt, hinter den Warzenfortsatz fällt, schneidet dieselbe beim drei- bis vierjährigen Kinde die Spitze des Fortsatzes, und fällt beim Erwachsenen weit vor dieselbe. 
Als Anhaltspunkte zur Bestimmung der Lage des Antrum mastoideum beim Erwachsenen bleiben uns demnach:

1. die nach hinten auseinanderweichenden Schenkel der Linea temporalis, besonders die dem absteigenden Schenkel angehörende Spina supra meatum, oder in Ermangelung derselben das dazu gehörige Grübchen. Wenn auch die Spina supra meatum mit der Entwicklung des Schläfebeins sich nach aussen rom Antrum entfernt, und zugleich mit dem Wachsthum des äussern Gehörganges nach rückwärts verschoben wird, so wird sie doch immer der wichtigste Anhaltspunkt zur Auffindung des Antrum bleiben, da die durch die Spina supra meatum gelegten Horizontalschnitte immer etwas oberhalb vom Boden des Antrum mastoideum durchfallen. Dieses constante Lageverhältniss von Antrum und Spina wurde für Erwachsene von Bezold ${ }^{1}$ ) nachgewiesen.

2. der Margo tympanicus squamae behält in allen Lebensaltern seine relative Lage, wie zur Paukenhöhle, so auch zum Antrum mastoideum. Da das Antrum mastoideum stets nach hinten und oben von dem hintern Theile des Margo tympanicus liegt, ist es nöthig, bei Aufsuchung desselben dic Richtung der obern hintern Gehörgangswand zu berücksichtigen. ${ }^{2}$ )

Zahlreiche Schnitte, die ich an Schläfebeinen Neugeborner, von Kindern bis zu vier Jahren, wie auch von Erwachsenen machte, zeigten, dass das Antrum mastoideum jedesmal getroffen wurde, wenn der Sägeschnitt in der Richtung derjenigen Tangentialebene des hinteren Paukenringrandes, resp. der hintern Peripherie des Porus acusticus externus (sogenannte Fissura tympanico-mastoidea) gefihrt wurde, welche das hintere Ende der Spina supra meatum beriihrt. Es ist also:

3. die vom hintern Ende der Spina supra meatum nach dem hintern Rande des Pankenringes, resp. des Porus acusticus externas gelegte Tangente in 'allen Lebensaltern ein Anhaltspunkt zur Auffindung des Antrum mastoideum. Bei Neugebornen trifft der in dieser Richtung geführte Sägeschnitt das Antrum squamosum, während er beim Erwachsenen regelmässig das Antrum petrosum eröffnet.

1) Bezold, Die Perforation des Warzenfortsatzes rom anatomischen Standpunkte aus. M. f. $0.1873, \mathrm{Nr} .11,1874, \mathrm{Nr}, \mathrm{l}$ u. 2, sowie Aerztliches Intelligenzblatt. 1874.

2) v. Tröltsch, Lehrbuch der Ohrenheilkunde. S. 496. Leipzig 1877. 
Ueber einige Veränderungen am Schläfebein in Folge von Rhachitis.

A. Ueber das Vorkommen nicht physiologischer Lücken im Schläfebein.

Abgesehen von älteren unsicheren Angaben ist Toyn be $\mathrm{e}^{1}$ ) wohl der erste, welcher derartige Fälle beobachtete. In seinem Cataloge sind 39 Fälle mit Oeffnungen der obern Paukenhöhlenwand verzeichnet. Ferner berichten uns über solche Hyrt $($ l. c.), Retzius ${ }^{2}$ ) und Luschka ${ }^{3}$ ).

Während Hyrtl die Entstehung solcher Lücken in den Wänden der pneumatischen Zellen anf gesteigerten Luftdruck in letztern zurückführt, nimmt $\mathrm{Lu}$ s chka an, dass die zottenartigen Vegetationen der Arachnoidea auch am Tegmen tympani durch Druck rareficirende Wirkungen hervorbringen.

Zuckerkand ${ }^{4}$ ) beschreibt einen Fall von bulböser Vorwölbung des Sinus sigmoideus, wo die Atrophie des Suleus sigmoideus so weit vorgeschritten war, dass an einer über haselnussgrossen Stelle die Pars mastoidea ossis temporum papierdïnn geworden war und eine durch einen Knochenkamm zweigetheilte Dehiscenz zeigt, durch welche der Bulbus des Sinus mit den weichen Schädeldecken in unmittelbare Berührung trat. Z. sagt hieruiber: "Es kann nicht geleugnet werden, dass die verschiedenen Druckverhältnisse, welchen der Sinus ausgesetzt werden kann, jene Anomalie hervorrufen. Ich neige jedoch der Ansicht zu, dass die Knochenatrophie primo loco in der Diploë des Warzenknochens auftritt und das Einsinken eines Stückes des Sulcus sigmoideus nebst consecutiver Erweiterung einer Portion des Sinus sigmoideus veranlasst.

Den stellenweise, zuweilen in grosser Zahl, von Mohnkornbis Linsengrösse auftretenden glasigen Verdünnungen des Sulcus sigmoideus, welche so häufig dehiseiren, schreitet ebenfalls stets ein Schwund der Diploë voran."

Hartmann ${ }^{5}$ ) beschreibt ein Schläfebein aus der Politzer-

1) A descriptive catalogue of praeparations illustrative of the diseases of the ear in the museum of Joseph Toynbee. London 1857.

2) Schmidt's Jahrbücher 1859.

3) Virchow's Archiv. XVIII. 1860.

4) Zuckerkand1, Beitrag zur Anatomie des Sehläfebeines. M. f. 0 . 1873. Nr.9. S. 106.

5) Hartmann, Ueber die Perforation des Warzenfortsatzes. Langenbeck's Archiv. XXI. 2. Heft. 
schen Sammlung, an dem der Sinus ohne ausgesprochene bulböse Form so stark nach aussen vorn vorgewölbt ist, dass im darüber liegenden Knochen eine $6 \mathrm{Mm}$. lange, $7 \mathrm{Mm}$. breite Knochenlücke entstanden ist. Der vordere Rand dieser Lijcke ist von der Spina supra meatum $5 \mathrm{Mm}$., der obere Rand von der Linea temporalis 3 Mm. entfernt.

Bürkner ${ }^{1}$ ) fand in 36 Fällen Lücken im Tegmen tympani, Dehiscenz der Paukenhöhle nach dem carotischen Kanale viermal und Lücken in der Fossa jugularis dreimal. Ferner war bei einem $11 / 2$ jährigen Kinde die Schuppe $5 \mathrm{Mm}$. über der Wurzel des Processus zygomaticus in einer Ausdehnung von 11/2 Cm. Höhe und $6 \mathrm{Mm}$. Breite so dünn, dass nichts als ein äusserst feines, um Lücken gruppirtes Knochenbalkennetz zu sehen ist, dessen Uebergang in die normale Substanz der Schuppe durch poröse Knochenmasse gebildet wird. Am linken Schläfenbeine dieses Schädels zeigt sich ausserdem eine ganz ähnliche, nur nicht ganz so liickenreiche Gegend im Sinus sigmoideus. Beiderseits ist das Tegmentum tympani blasenartig aufgetrieben, durchscheinend und von mehreren Löchern durchsetzt.

An dem Schädel eines Erwachsenen fand B. im dünnen rechten Sinus sigmoideus eine nach aussen mündende Lïcke von $3 \mathrm{Mm}$. Durchmesser.

Bürkner ist der Ansicht, dass die häufig constatirten, nicht durch Entzündungsprocesse verursachten Liteken im Tegmen tympani und an andern Stellen der Schädelhöhle in der uberwiegenden Mehrzahl der Fälle vom Drucke des Gehirns herrühren. -

Ausser den oben beschriebenen physiologisehen Ossificationslïcken habe ich an normalen Schläfebeinen Heranwachsender niemals Dehiscenzen der das Mittelohr umgebenden Knochenwände gesehen. Dagegen finden sich solche Dehiscenzen reichlich an den Schläfebeinen rhachitischer Kinder.

Die rhachitischen Veränderungen können an allen Theilen des Schläfebeins vorkommen, mit Ausnahme der Labyrinthwände, wenigstens waren letztere in den von mir untersuchten Fällen immer intact.

Der Paukentheil wird verhältnissmässig selten befallen, und auch dann meist nur der am hintern Schenkel neugebildete Knochen,

Vom horizontalen Theile der Schuppe ist der hintere Theil,

1) Bürkner, Zur sogenannten Dehiscenz des Tegmen tympani. A. f. 0 . XIII. 1878. S. 185 . 
nämlich die obere Gehörgangswand, seltener befallen, während der vordere Theil, Processus articulares und Gelenkgrube, häufiger an der Erkrankung theilnehmen.

Unter zwanzig rhachitischen Schläfebeinen meiner Sammlung ist das Tegmentum tympani siebenmal betheiligt, davon funfmal nur die Decke des Antrum, and nur in zwei sebr hochgradigen Fällen auch der vordere Theil, die Paukenhöhlen- und Tubendecke. Unter diesen sieben Fällen befinden sich vier mit Dehiscenzen im hintern Theil, welche zum Antrum führen.

Ein Durchbruch der Wand zwischen Sulcus transversus und Antrum ist einmal vorhanden.

Der Theil des Bodens der Paukenhöhle, welcher von der Decke der Fossa jugularis gebildet wird, fehlt in vier Fällen ganz, in neun anderen Fällen ist nur wenig melr davon vorhanden.

Die Wand des Canalis carotieus ist durchbrochen: gegen die Tuba Eustachii in drei Fällen, in zwei weiteren gegen Tuba und Paukenhöhle.

Ausserdem finden sich noch Lücken in der Aussenwand des Sulcus sigmoideus in fünf Fällen, und in drei Fällen Durchlöcherung der Schuppe vor dem obern Theile der Linea temporalis.

Die eben erwähnten Schläfebeine stammen sämmtlich von Kindern aus dem Alter von $1 / 2$ bis zu 4 Jahren. Die Juga cerebralia und Impressiones digitatae sind selbstverständlich an den jüngern Schläfebeinen wenig ausgeprägt, ebenso bei den noch stärker afficirten älteren. Dagegen sind Juga und Impressiones bei den etwa vierjährigen, wenig mehr afficirten Schläfebeinen sebr stark ausgeprägt. Es versteht sich von selbst, dass bei der geringen Anzahl der mir zu Gebote stehenden rhachitischen Schläfebeine letatere Angaben nicht als allgemein maassgebende angesehen werden können.

Es ist nun wobl denkbar, dass an den Stellen, die bereits durch den auf ihnen lastenden Druck bis zur Bildung von Knochenlüeken rareficirt sind, bei weiterer Einwirkung dieses Druckes eine Knochenneubildung nicht stattindet, sondern dass diese Lỉcken persistiren. Ich stimme also mit $B$ ürkner vollständig darin überein, dass als Cansa externa dieser Lückenbildung der Druck der Gehirnwindungen etc. angesehen werden muss, möchte aber als Causa interna die geringere Widerstandsfähigkeit des rhachitischen Knochens hinzufügen. Als weiteren Beleg für diese Ansicht 
werde ich unten die Beschreibung der Residuen von Rhachitis an dem Schädel eines Erwachsenen geben.

Die Ansichten von Luschka und Zuckerkandl sind wohl auf einfache Altersveränderungen zu beziehen.

\section{B. Ueber Infractionen der Lamina externa.}

Eine weitere Anomalie in Folge von Rhachitis, welche auch unter Umständen von bedeutender praktischer Wichtigkeit sein kann, besteht in der Impression der Lamina externa des hintern Schuppentheils, also der äussern Wand des Antrum mastoideum der Neugebornen. Angaben über das Vorkommen derselben bei Erwachsenen finde ich nur bei Bezold.1) Derselbe fand diese Formveränderung unter 100 Schädeln dreimal, und sind dieselben in den Bemerkungen über auffällige Formverhältnisse einzelner Schläfenbeine angeführt.

Fall 2. Links unter der Linea temporalis hinter der Spina supra meatum findet sich ein tiefer Eindruek im Knochen and die Oberfläche in dieser Vertiefung uneben, jedoch wahrscheinlich nicht in Folge von Caries, da rechts eine ähnliche unebene Vertiefung an der genau correspondirenden Stelle, nur viel weniger ausgesprochen, vorhanden ist. Dieser Einsenkung entspricht die hier nngewöhnlich nach vorn gertickte Lage der dünnsten Stelle der Pars mastoidea. Die Fissura mastoideo-squamosa befindet sich $13 \mathrm{Mm}$. von der Spina supra meatum entfernt and hat keinen Bezug zu der vertieften Stelle.

Fall 39. Beiderseits, links mehr als rechts, befindet sich eine tief eingedrückte Grube unterhalb der Linea temporalis.

Fall 45. Links fällt die weit nach vorne liegende diunnste Stelle in die stark ausgeprägte verticale Rinne, welche als Rest der embryonalen Fissura mastoideo-squamosa persistirt.

Ich fand diese Einsenkung an kindlichen Schläfenbeinen nur bei rhachitischen, und scheint dieselbe nicht so gar selten $\mathrm{zu}$ sein, da acht von meinen zwanzig rhachitisehen Schläfenbeinen dieselbe zeigen. Bald ist nur das über der Spina supra meatum gelegene Griibchen ungewöhnlich verbreitert und vertieft; in andern Fällen gesellt sich dazu eine tiefe, mehr vertical verlaufende Einsenkung, die der Fissura mastoideo-squamosa bald näher, bald ferner liegt, aber immer den Schuppenrand derselben beträchtlich nach einwärts zieht. In den leichtesten Fällen kommt diese ver-

1) Bezold, Die Perforation des Warzenfortsatzes etc. M. f. 0.1874. Nr. 1. S. 6.

Archiv f. Ohrenheilkunde. XV. Bd. 
ticale Einsenkung gewöhnlich allein vor. In den schwersten Fällen ist der ganze Raum zwischen den beiden Schenkeln der Linea temporalis und der Fissura mastoideo-squamosa gleichmässig tief eingesunken.

Ich glaube daher, dass alle Fälle von Einsenkung der Schuppe Erwachsener an dieser Stelle Folgezustände überstandener Rhachitis sind. Ebenso möchte ich auch die Fälle von tiefen Spalten, die wir mitunter am Schuppentheil des Warzenfortsatzes, und zwar immer in geringer Entfernung vor der Fissura mastoideosquamosa finden, für Residuen jener verticalen Einsenkung an rhachitischen Kinderschläfenbeinen halten. In der Ansicht von dem rhachitischen Ursprunge dieser Gruben und Spalten musste ich dadurch bestärkt werden, dass, abgesehen von andern Zeichen iiberstandener Rhachitis, sich bei dem Vorhandensein solcher Gruben und Spalten ungewöhnlich häufig Tiefstand der mittleren Schädelgrube vorfand, der in einzelnen Fällen einen sonst wohl kaum beobachteten Grad erreicht. Dieses Eingesunkensein des äussern Theils der obern Felsenbeinkante und der vordern obern Wand des Felsentheils zwischen Schädelwand und der Gegend des obern halbcirkelförmigen Kanals, welches wir nach Hartmann (1. c.) als Tiefstand der mittlern Sehädelgrube bezeichnen, ist aber kaum anders zu erklären, als durch den Druck der darïber liegenden Gehirnwindung auf hochgradig erweichten Knochen.

Die prägnantesten der hierher gehörigen, an Schläfenbeinen Erwachsener beobachteten Anomalien sind folgende:

Fall 1. Die rautenförmige Einsenkung beginnt beiderseits unmittelbar unter der First der Linea temporalis über dem vordern Ende der Spina supra meatum und erstreckt sich von da nach hinten, so dass der hintere spitze Winkel der Raute gerade unterhalb der Incisura parietalis (beiderseits etwa $7 \mathrm{Mm}$. unter derselben) zu liegen kommt. Den grössten Theil des vordern untern Randes bildet die Spina supra meatum. Die Durchmesser der Grube betragen von vorn nach hinten $15,5 \mathrm{Mm}$., von oben nach unten rechts 15,0, links 13,5 Mm. Der Grund der Grube ist durchscheinend, da die Aussenwand der mittleren Schädelgrube, welche den Boden der Einsenkung im grössern obern Theil bildet, bis auf nahezu $2 \mathrm{Mm}$. verdunnt ist. Der Tiefstand der mittleren Schädelgrube ist besonders auf der linken Seite so hochgradig, dass der Boden derselben nur wenig höher als die Spina supra meatum steht. Beide Pori acustici externi 
sehen aus, als ob sie von oben nach unten zusammengedrückt seien.

Im Innern ist an der Schädelbasis zu bemerken:

1. Die hinteren Schädelgruben sind ungewöhnlich flach und der Clivus wenig geneigt. Der rechte Sulcus sigmoideus ist stark nach vorn gewölbt, so dass seine vordere Wand in gleicher Frontalebene mit dem hintern Winkel der äussern Grube liegt. Der linke Sulcus verläuft dagegen annähernd normal.

2. Die obere Kante des Felsentheils ist an ihrem Uebergange auf die Pars mastoidea stumpfwinklig eingebogen, und der äussere hintere Theil des Tegmen tympani eingedriickt.

3. Das Tegmentum tympani ist blasig aufgetrieben, an einzelnen Stellen durchscheinend. Am äussern Theile desselben ist die Corticalis rechts von einer rundlichen Oeffnung von ca. $3 \mathrm{Mm}$. Durchmesser durchbrochen, links fehlt die vom Tegmen tympani und Lamina interna gebildete Zellendecke in einer Ausdehnung 'von $13 \mathrm{Mm}$. Länge und $6 \mathrm{Mm}$. Breite fast vollständig.

Fall 2. Auf der rechten Seite verläuft eine tiefe blinde Einsenkung, 6,5 Mm. vor der Incisura parietalis, 4,5 Mm. unterhalb derselben beginnend, von dieser Stelle nach abwärts, um etwa in der Höhe des untern Randes des Porus acusticus externus an der Sutura mastoideo-squamosa zu enden. Linkerseits befindet sich eine Grube, ähnlich den im vorigen Falle beschriebenen, doch ist dieselbe durch eine Knochenleiste von der Spinalgrube getrennt. Von dem untern Winkel dieser Grube geht eine ähnliche Einsenkung nach abwärts, wie rechts, um in gleicher Weise zu enden. Der Boden der mittleren Schädelgrube steht links ebenfalls fast in gleicher Höhe mit der Spina supra meatum, während er sich rechts etwas höher befindet.

Diese beiden Fälle werden genügen, um die vollständige Uebereinstimmung der beschriebenen abnormen Verhältnisse mit den an.rhachitischen Kinderschläfenbeinen wahrgenommenen Veränderungen darzuthun. Die Ursache dieser Infractionen der Lamina externa ist wohl in dem Druck des Ohres auf die erweichte, dünne Knochenlamelle zu suchen.

Dass aber in praktischer Hinsicht das Vorkommen dieser Gruben und Spalten bei Vornahme der Perforation des Warzenfortsatzes, zur äussersten Vorsicht auffordern muss, liegt auf der Hand. 
270 XIV. KIESSELBACH, Normale und pathol. Anatomie d. Schläfenbeins.

$$
\begin{gathered}
\text { Erklärung der Abbildungen. } \\
\text { (Taf. VL.) }
\end{gathered}
$$

Fig. 1 und 2. Normale Schläfenbeine des Neugebornen.

Fig. 1 mit, Fig. 2 ohne den obersten Theil der Fissura mastoideo-squamosa.

Fig. 3. Klaffende Spalte der Fissura mastoideo-squamosa (31/2 jähriges Mädchen).

Fig. 4 und 5. Abnormes Verhältniss von Processus tympanicus squamae und Spitze des Warzenfortsatzes. Zwischen beiden eine $3 \mathrm{Mm}$. breite Spalte (21/2 jähriger Knabe).

Fig. 6-9. Ossificationslitcken in der Lamina externa des hintern Schuppentheils.

6) Schläfenbein eines Neugebornen.

7) Schläfenbein eines $31 / 2$ jährigen Knaben.

8) Schläfenbein eines 17 jährigen Jünglings.

9) Schläfenbein eines Erwachsenen.

Fig. 10. Abnorme Naht zwischen Processus mastoideus und hinterer Partie des Warzentheils.

Fig. 11. Dasselbe Schläfenbein von hinten gesehen.

Fig. 12. Infraction der Lamina externa des hintern Schuppentheils in Folge von Rhachitis (Schläfenbein eines Erwachsenen). 